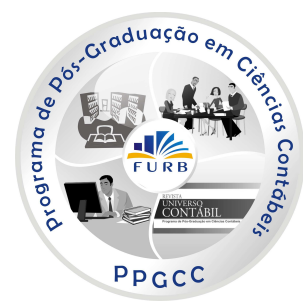

\title{
AVALIAÇÃO E DIVULGAÇÃO DE INDICADORES DE DESEMPENHO DOS MUNICÍPIOS PORTUGUESES: O CASO DO DISTRITO DE SETÚBAL1
}

\section{EVALUATION AND DISCLOSURE OF PERFORMANCE MEASURES ON PORTUGUESE LOCAL GOVERNMENTS: THE CASE OF SETÚBAL DISTRICT \\ EVALUACIÓN Y DIVULGACIÓN DE LOS INDICADORES DE DESEMPEÑO DE LOS MUNICIPIOS DE PORTUGAL: EL CASO DE LO DISTRITO DE SETÚBAL}

\begin{abstract}
Ana Bela Teixeira
Doutora em Gestão, Especialidade Contabilidade pela Universidade Aberta Professora da Escola Superior de Ciências Empresariais do Instituto Politécnico de Setúbal

Endereço: Campus do IPS, Estefanilha, CEP: 2914-503 - Setúbal - Portugal E-mail: ana.bela.teixeira@esce.ips.pt Telefone: +351265 709362

Carlos Mata

Mestre em Gestão pelo Instituto Superior de Ciências do Trabalho e da Empresa Professor da Escola Superior de Ciências Empresariais do Instituto Politécnico de Setúbal Endereço: Campus do IPS, Estefanilha, CEP: 2914-503 - Setúbal - Portugal

E-mail: carlos.mata@esce.ips.pt Telefone: +351265709300

Pedro Nuno Pardal Mestre em Contabilidade pelo Instituto Superior de Ciências do Trabalho e da Empresa Professor da Escola Superior de Ciências Empresariais do Instituto Politécnico de Setúbal Endereço: Campus do IPS, Estefanilha, CEP: 2914-503 - Setúbal - Portugal

E-mail: pedro.pardal@esce.ips.pt Telefone: +351265709300

Nuno Teixeira

Mestre em Gestão pelo Instituto Superior de Ciências do Trabalho e da Empresa Professor da Escola Superior de Ciências Empresariais do Instituto Politécnico de Setúbal Endereço: Campus do IPS, Estefanilha, CEP: 2914-503 - Setúbal - Portugal

E-mail: nuno.teixeira@esce.ips.pt Telefone: +351265709300
\end{abstract}

\footnotetext{
1 Artigo recebido em 28.03.2012. Revisado por pares em 02.05.2012. Reformulado em 25.06.2012. Recomendado para publicação em 27.06.2012 por Ilse Maria Beuren. Publicado em 31.03.2013. Organização responsável pelo periódico: FURB.
} 


\section{RESUMO}

A aplicação do POCAL deverá permitir a obtenção de indicadores de diversas ordens, nomeadamente, orçamentais, patrimoniais e de custos. Estes deverão possibilitar a análise de desempenho das autarquias locais medindo níveis de economia, eficiência e eficácia, e que sirvam de apoio à gestão autárquica. $O$ objectivo do presente estudo centra-se na caracterização da informação sobre o desempenho dos municípios do distrito de Setúbal, com base no Anuário Financeiro dos Municípios Portugueses e nos indicadores apresentados no Relatório de Gestão. Os resultados demonstram que os municípios apresentam fundamentalmente indicadores de carácter orçamental e/ou patrimonial, facto justificado pela fraca implementação da contabilidade de custos. Apesar de 3 municípios não apresentarem qualquer indicador nos seus Relatórios de Gestão, os restantes apresentam no total, 159 indicadores diferentes, sendo 115 de carácter orçamental e 44 económicos e/ou patrimoniais. Contudo, identificou-se que parte dos indicadores apresentados são baseados em conceitos da contabilidade empresarial e que não existe uma uniformização da divulgação entre municípios, sendo um claro limite à análise comparativa de desempenho. Através da elaboração de um ranking de desempenho para o distrito de Setúbal confirmámos que os municípios melhores posicionados são os de Alcácer do Sal, Almada e Grândola.

Palavras-chave: Contabilidade. POCAL. Autarquias locais. Avaliação de desempenho. Indicadores.

\section{ABSTRACT}

The application of POCAL should permit the calculation and presentation of different indicators of performance, including measures from budget information, financial and cost accounting. These indicators should enable the analysis of local governments' performance based on measuring the levels of economy, efficiency and effectiveness, serving as a support for management. The purpose of this study focuses on characterizing the existing information about of the local governments in Setúbal district, which is included in the Annual Financial Report of Portuguese Municipalities and on the indicators presented in Management Report. This analysis showed that the indicators of municipalities have a budgetary and/or financial nature, justified by the poor implementation of cost accounting. Despite 3 of the local governments didn't present any indicator on their management reports, the other entities presented a total 159 different indicators, being 115 from budgetary information and 44 of financial nature. However, evidence showed that part of the indicators are based on accounting measures used on private sector and also showed that there isn't a standardization of local governments disclosures, what is a clear limit to a comparative analysis of performance. Also, through the development of a performance ranking for Setúbal district, we confirmed that Alcácer do Sal, Almada and Grândola are the local governments best positioned.

Keywords: Accounting. POCAL. Local government. Performance measurement. Indicators.

\section{RESUMEN}

La aplicación de POCAL debería permitir el desarrollo de indicadores de diversas índoles, incluida la presupuestaria, equidad y el costo. Éstos deben permitir el análisis de rendimiento e los locales de los niveles de medición de la economía, eficiencia y eficacia, y servir de apoyo a la gestión municipal. El objetivo de este estudio se centra en la caracterización de la información sobre el desempeño de los municipios en el distrito de Setúbal, con base en el Informe Financiero Anual de Municipios Portugueses e indicadores presentados en el 
Informe de Gestión. Los resultados muestran que los municipios son los principales indicadores de una situación presupuestaria naturaleza y / o la equidad, ya sea justificado por la mala aplicación de la contabilidad de costos. A pesar de los tres municipios no han presentado ningún indicador en su informe de gestión, el resto tiene un total de 159 indicadores diferentes de carácter presupuestario siendo 115 y 44 económicas y / o propiedad. Sin embargo, encontramos que algunos de los indicadores que se presentan se basan en conceptos de la contabilidad de las empresas y no existe una estandarización de la comunicación de información entre los municipios como un límite claro para el análisis comparativo de rendimiento. A través de la elaboración de un ranking de desempeño para el distrito de Setúbal confirmó que los municipios están en mejores condiciones de Alcacer do Sal, Almada y Grândola.

Palabras clave: Contabilidad. POCAL. Los gobiernos locales. Evaluación de resultados. Indicadores.

\section{INTRODUÇÃO}

A aprovação do Plano Oficial de Contabilidade das Autarquias Locais (POCAL) implicou uma profunda alteração nos sistemas contabilísticos das autarquias locais em Portugal. Esta nova realidade deverá permitir dotar as autarquias locais de mais e melhor informação para a gestão, permitindo a avaliação do seu desempenho por um conjunto de indicadores de cariz orçamental, patrimonial e baseados na contabilidade analítica. Neste enquadramento, diversos estudos de âmbito nacional têm vindo a debruçar-se sobre a implementação e o tratamento da informação decorrente da aplicação do POCAL, destacando-se neste âmbito o Anuário Financeiro dos Municípios Portugueses (AFMP) como um documento nacional de análise à prestação de contas dos municípios. Contudo, este documento, como veremos, não permite o total detalhe da avaliação de desempenho por cada município, os quais podem apresentar características e um enquadramento totalmente distintos. Desta forma, e tendo presente que os municípios do distrito de Setúbal tiveram igualmente de se adaptar a uma nova prática contabilística, o presente estudo tem como objectivo geral, identificar e caracterizar de forma mais detalhada a informação sobre o seu desempenho, tendo por base os seus documentos de prestação de contas. Esta análise terá diferentes perspectivas, que se concretizam nos seguintes objectivos específicos:

- Análise da informação constante do AFMP relativamente aos municípios do distrito de Setúbal;

- Elaboração de um ranking global de desempenho para os municípios do distrito de Setúbal;

- Análise à informação por indicadores constantes nos Relatórios de Gestão destas entidades.

Neste sentido, o presente documento inicia-se com uma caracterização da contabilidade no sector local, resumindo as principais características dos sistemas contabilísticos estabelecidos no POCAL. De seguida, é efectuada uma revisão de literatura aos estudos existentes sobre a análise da prestação de contas pelos municípios e sobre a importância dos indicadores de gestão, procurando evidência de informação sobre municípios do distrito de Setúbal. Posteriormente, é apresentado o estudo empírico, caracterizando a amostra, identificando a informação relevante sobre as entidades seleccionadas e que consta do AFMP, bem como, a elaboração e apresentação do seu ranking global. Igualmente, neste ponto são identificados e analisados os indicadores divulgados nos Relatórios de Gestão. Por fim, nas considerações finais é efectuado um resumo dos principais resultados do estudo e são apresentadas as linhas futuras de investigação. 


\section{A CONTABILIDADE NAS AUTARQUIAS LOCAIS}

O POCAL foi aprovado em 1999, com o Decreto-Lei n54-A/99, de 22 de Fevereiro, e representou um marco na contabilidade autárquica em Portugal. O POCAL vem introduzir nas autarquias um novo sistema contabilístico, alinhado com o Plano Oficial de Contabilidade Pública (POCP), mas que ao mesmo tempo fosse capaz de responder às necessidades particulares de prestação de contas das entidades do sector autárquico. O POCAL foi o primeiro plano sectorial a ser aprovado no âmbito do sector público e decorrente da aprovação do POCP, devendo ser aplicado a todas as autarquias locais e entidades equiparadas, como por exemplo, as áreas metropolitanas, assembleias distritais ou associações de freguesias. $\mathrm{O}$ ano de aplicação estabelecido para o exercício económico de 2000 foi contudo adiado para 2002 em virtude de dificuldades sentidas pelas entidades na elaboração do seu inventário e na valorização do seu Balanço inicial.

No seu preâmbulo, O POCAL estabelece como principal objectivo a criação de condições para a integração consistente da Contabilidade Orçamental, Patrimonial e de Custos numa contabilidade pública moderna, que constitua um instrumento fundamental de apoio à gestão das autarquias locais e permita, entre outros aspectos:

- O controlo financeiro e a disponibilização de informação para os órgãos autárquicos, concretamente o acompanhamento da execução orçamental numa perspectiva de caixa e de compromissos;

- A obtenção expedita dos elementos indispensáveis ao cálculo dos agregados relevantes da contabilidade nacional;

- A disponibilização de informação sobre a situação patrimonial de cada autarquia local (conhecimento integral e exacto da composição do património autárquico);

- A tomada de decisões estratégicas no domínio da orçamentação plurianual, face ao acompanhamento de compromissos com reflexos em anos futuros;

- A possibilidade de determinar correctamente, através da contabilidade de custos, o real custo de cada um dos serviços prestados, actividades e acções levadas a cabo pelas autarquias.

Desta forma, podemos verificar que os objectivos se centram essencialmente na quantidade e qualidade da prestação de contas autárquica e em proporcionar os meios para a obtenção de informação de apoio à gestão das autarquias. Esta informação deverá ser essencial à obtenção de melhorias em termos de economicidade, eficiência e eficácia, devendo igualmente facilitar a análise de indicadores e a avaliação de desempenho no sector local. Para tal, o POCAL define um sistema de informação assente em três sistemas contabilísticos, nomeadamente o Orçamental, Patrimonial e de Custos. No quadro 1 apresenta-se resumidamente as características de cada um destes sistemas.

Os três sistemas de contabilidade são de aplicação obrigatória, embora o Tribunal de Contas apenas fiscalize os documentos produzidos pelo sistema de Contabilidade Orçamental e Patrimonial. No entanto e de acordo com Carvalho et al. (2009), alguns mapas da contabilidade custos (custos de cada bem ou serviços) deveriam ser igualmente integrados nos documentos de prestação de contas.

Quanto à Contabilidade Orçamental, mediante o uso da classe 0, esta permite prestar informação para controlar parte da execução orçamental das autarquias locais, nomeadamente o controlo dos cabimentos e assunção de compromissos assentes na verificação de regularidade financeira. Em conjugação com o uso da conta 25 (Devedores e Credores pela execução do orçamento) na contabilidade patrimonial permite o acompanhamento da execução orçamental até ao seu final (recebimento de receitas ou pagamento de despesas) e a sua comparação com as previsões iniciais. 
Quadro 1 - A Contabilidade Orçamental, Patrimonial e de Custos no POCAL

\begin{tabular}{|c|c|c|c|}
\hline & Contabilidade Orçamental & Contabilidade Patrimonial & Contabilidade de Custos \\
\hline Aplicação & Obrigatória & Obrigatória & Obrigatória \\
\hline $\begin{array}{c}\text { Base de } \\
\text { Reconhecimento }\end{array}$ & $\begin{array}{l}\text { Base de Caixa e de } \\
\text { Compromissos }\end{array}$ & Base de Acréscimo & Base de Acréscimo \\
\hline Contas do Plano & Classe 0 e Conta 25 & Classes 1 a 8 & $\begin{array}{l}\text { Não é atribuída nenhuma } \\
\text { Classe }\end{array}$ \\
\hline Método de Registo & Digráfico & Digráfico & Omisso \\
\hline Classificação & $\begin{array}{l}\text { Classificação Económica das } \\
\text { Despesas e Receitas }\end{array}$ & Modelo tipo Empresarial & Classificação Funcional \\
\hline $\begin{array}{l}\text { Mapas obtidos, } \\
\text { principais } \\
\text { informações e } \\
\text { outras } \\
\text { características }\end{array}$ & $\begin{array}{l}\text { - } \text { Controlo Orçamental } \\
\text { - Mapas Orçamentais com } \\
\text { informação de todas as } \\
\text { fases da despesa e da } \\
\text { receita } \\
\text { - PPI - Plano Plurianual de } \\
\text { Investimento } \\
\text { - Documentos Previsionais } \\
\text { - Informação de } \\
\text { compromissos de } \\
\text { exercícios futuros }\end{array}$ & $\begin{array}{l}\text { - Demonstração dos } \\
\text { Resultados por Natureza } \\
\text { - Balanço Patrimonial } \\
\text { - Valor actual do } \\
\text { Imobilizado } \\
\text { - Valor das Dívidas } \\
\text { - Valor dos Stocks } \\
\text { - Resultados Económicos } \\
\text { - Bens de Domínio Público } \\
\text { no Activo }\end{array}$ & $\begin{array}{l}\text { - Demonstração dos } \\
\text { Resultados por Funções } \\
\text { (facultativo) } \\
\text { - Fichas de Contabilidade de } \\
\text { Custos } \\
\text { - Apuramento dos custos dos } \\
\text { bens e serviços, para a } \\
\text { fixação das tabelas de tarifas } \\
\text { e preços } \\
\text { - Reclassificação de custos em } \\
\text { directos (materiais, mão-de- } \\
\text { obra, máquinas e viaturas e } \\
\text { outros) e indirectos } \\
\text { - Sistema de Custeio Total } \\
\text { - Método de Repartição de } \\
\text { Base Única }\end{array}$ \\
\hline
\end{tabular}

Fonte: Adaptado de Carvalho et al. (1999).

O POCAL desenvolve igualmente regras orçamentais alinhadas com a Lei de Enquadramento Orçamental (LEO) e um conjunto de directrizes e mapas que visam a elaboração previsional de mapas de cariz orçamental. De destacar a obrigatoriedade de se elaborar o Plano Plurianual de Investimentos (PPI) que resulta numa orçamentação do investimento a quatro anos e que deve consubstanciar-se nas Grandes Opções do Plano. $\mathrm{O}$ controlo de execução do PPI e do Orçamento revela indicadores extremamente importantes sobre a concretização dos objectivos traçados pelas entidades autárquicas para as suas actividades. Por outro lado, a informação decorrente da Contabilidade Patrimonial é essencial para a valorização e controlo do património de cada autarquia, permitindo a obtenção de um Balanço e de uma Demonstração de Resultados, entre outra informação, nomeadamente sobre os níveis de endividamento das autarquias, dando resposta às exigências da nova Lei das Finanças Locais (Lei n²/2007, de 15 de Janeiro).

De referir que de forma genérica, nas autarquias e tal como nas restantes entidades públicas, a produção de bens ou a prestação de serviços, pelo cariz social da sua existência, o lucro não pode ser o objectivo final, nem uma boa medida de desempenho para a medição da economia, eficiência e eficácia das autarquias. Por outro lado, a Contabilidade Patrimonial só evidencia o que se fez e o que existe, não fornecendo informação sobre as melhorias que poderão ser realizadas e como se processa a criação ou a formação de valor no seio da organização. Tal como refere Caiado (2002) ela é insuficiente para dar resposta às necessidades de informação para a gestão, dado que se trata de uma contabilidade do passado, cujas informações têm falta de actualidade e estão submetidas a normas rígidas, tendo como objecto o controlo das relações com terceiros, a revelação das variações patrimoniais e o apuramento do resultado global. Para gerir com economia e eficiência é necessário possuir um sistema de Contabilidade de Custos, que disponibilize as informações necessárias à redução e controlo de custos dada a importância do controlo financeiro e da análise da eficácia nas entidades locais (Correia, 2002).

Neste âmbito o POCAL define um sistema de Contabilidade de Custos, resumindo-se na prática ao apuramento do custo dos bens e serviços. Estas regras para a elaboração da 
Contabilidade de Custos, apresentadas pelo POCAL, são contudo relevantes para a uniformização do apuramento dos custos dos bens e serviços, para que não existam grandes diferenças entre as tabelas de tarifas e preços das diversas autarquias (Costa e Carvalho, 2006). Desta forma verifica-se que o sistema de Contabilidade de Custos, tal como definido no POCAL, deverá apoiar as exigências previstas no Regime Geral de Taxas, da Lei n 53 E/2006 de 29 de Dezembro, que obriga no $\mathrm{n}^{\circ} 2$ do seu art. ${ }^{\circ} 8$, a que "o regulamento que crie taxas municipais ou taxas das freguesias contém obrigatoriamente, sob pena de nulidade: a) A indicação da base de incidência objectiva e subjectiva; b) $\mathrm{O}$ valor ou a fórmula de cálculo do valor das taxas a cobrar; c) A fundamentação económico-financeira relativamente ao valor das taxas, designadamente os custos directos e indirectos, os encargos financeiros, amortizações e futuros investimentos realizados ou a realizar pela autarquia local", entre outros aspectos.

Assim, e apesar de algumas insuficiências apontadas essencialmente à Contabilidade de Custos, verificamos que os três sistemas contabilísticos permitem a elaboração de indicadores de desempenho das autarquias sobre diferentes ópticas, o qual é concretizado de forma obrigatória pela prestação de contas ou através de divulgação por estudos independentes, como é o caso do Anuário Financeiro dos Municípios Portugueses (AFMP).

\section{ESTUdOS SOBRE A DIVULGAÇÃO E ANÁLISE DE INDICADORES NOS MUNICÍPIOS}

Os diversos estudos existentes sobre a divulgação e importância de indicadores nas autarquias retratam essencialmente a realidade nacional, sendo praticamente nulo o tratamento de informação específica sobre os municípios do distrito de Setúbal, com excepção do AFMP em que podemos encontrar alguma informação nos rankings apresentados por município e por indicador. De uma forma genérica, os estudos efectuados analisam essencialmente a divulgação de indicadores com base nas demonstrações financeiras e orçamentais, bem como, a prática de divulgação de indicadores no Relatório de Gestão, tal como exigido no POCAL. Por outro lado, diversos investigadores têm-se debruçado sobre a importância dos indicadores de gestão para as autarquias. Para Serra, Carvalho e Costa (2007) exige-se uma contabilidade pública que promova indicadores capazes de auxiliar a tomada de decisões, medir o desempenho das entidades, bem como planear e controlar a situação económico-financeira das mesmas. Contudo, os diversos estudos têm-se deparado com uma fraca implementação de indicadores que tenham por base contabilidade analítica e que permitam medir de forma melhorada a economia, eficiência e eficácia da gestão dos seus recursos.

No âmbito da análise às demonstrações financeiras e orçamentais, o AFMP é o documento nacional de referência, sintetizando a avaliação do desempenho das autarquias através de uma análise de diversos indicadores tendo por base a prestação de contas anual de cada município português. O AFMP surge de um projecto liderado pelo Prof. Dr. João Carvalho, tendo sido iniciado com a análise à prestação de contas referente ao exercício económico de 2003. Na sua última versão disponível e editada em 2010, respeitante ao exercício económico de 2008, o AFMP debruça-se essencialmente sobre a análise da informação orçamental e patrimonial, assentando a sua abordagem, após um capítulo sobre a organização do sector local e o enquadramento da contabilidade e finanças municipais, nos seguintes pontos: $(i)$ análise da execução orçamental dos municípios, nomeadamente com a análise detalhada das receitas e despesas autárquicas, e de indicadores de cariz orçamental; (ii) análise financeira, económica e patrimonial dos municípios, assentando essencialmente numa análise às rubricas do Balanço e Demonstração de Resultados; (iii) análise dos rácios de endividamento, de acordo com as exigências da Lei das Finanças Locais; e (iv) análise às contas do sector empresarial local e dos serviços municipalizados. Gonçalves, Correia e 
Marques (2011) efetuaram um estudo de caso sobre o desempenho do município de Oliveira do Hospital tendo por base a estrutura de análise do AFMP de 2008 e através do qual fazem uma comparação com o desempenho médio nacional dos municípios. Na análise à informação divulgada por este município, os autores referem que o ênfase mantem-se na informação orçamental, em detrimento da informação patrimonial, económica e financeira.

A análise às contas dos municípios feita no AFMP é apresentada numa perspectiva nacional, identificando-se através de rankings os maiores/melhores e menores/piores municípios para os mais diversos indicadores. Por outro lado, e de forma a melhorar a comparabilidade entre municípios, a análise é normalmente enquadrada pela dimensão dos municípios (grandes, médios e pequenos). Neste sentido, numa análise aos indicadores dos municípios do distrito de Setúbal apenas é possível de identificar aqueles que se inserem nos mais ou menos em cada indicador. Um dos objectivos do presente documento é a identificação no AFMP das referências sobre o desempenho dos municípios do distrito de Setúbal, pelo que, a mesma será desenvolvida no capítulo seguinte. O AFMP apresenta no final um ranking global de desempenho dos municípios como conjugação do seu desempenho em diversos indicadores de cariz orçamental e patrimonial (incluindo indicadores de endividamento). Da mesma forma, e em virtude de o AFMP evidenciar apenas parte da situação dos municípios que são âmbito do nosso trabalho, neste documento efectuar-se-á a elaboração de um ranking global de desempenho, apenas para os municípios do distrito de Setúbal, seguindo a metodologia de base adoptada no AFMP.

Outro aspecto importante de divulgação de indicadores prende-se com a informação que deve constar no Relatório de Gestão que de acordo com o ponto 13 do POCAL deve contemplar os seguintes aspectos: "A situação económica relativa ao exercício, analisando em especial a evolução da gestão dos diferentes sectores de actividade da autarquia local, designadamente no que respeita ao investimento, condições de funcionamento, custos e proveitos, quando aplicável; Uma síntese da situação financeira da autarquia, considerando os indicadores de gestão financeira apropriados à análise de balanços e de demonstrações de resultados; Evolução das dívidas de curto, médio e longo prazo, de terceiros e a terceiros, nos três últimos anos, individualizando, naquele último caso, as dívidas a instituições de crédito das outras dívidas a terceiros; Proposta fundamentada da aplicação do resultado líquido do exercício; Os factos relevantes ocorridos após o termo do exercício." Contudo, se por um lado o POCAL faz referência à necessidade dos municípios apresentarem indicadores de gestão no Relatório de Gestão, por outro, não define que tipos de indicadores devem ser apresentados. Deste modo, é possível que um indicador tenha significados diferentes para cada município. Segundo Carvalho, Fernandes e Teixeira (2006) o Relatório de Gestão deve proporcionar uma visão clara da situação orçamental, financeira, patrimonial e económica relativa ao exercício, reflectindo a eficiência na utilização dos meios afectos à realização das actividades desenvolvidas pelo município e a eficácia na concretização dos objectivos. Igualmente defendem a necessidade de uma normalização dos indicadores mínimos a apresentar por cada município.

Internacionalmente diversos estudos têm-se debruçado sobre propostas de instrumentos e indicadores para medir o desempenho dos municípios (Hood, 1991; Barzelay, 2001). Já Ahmad e Broussine (2003) e Galera, Rodríguez e Hernández (2008) vêm reforçar que a relevância e utilidade das medidas de desempenho aumenta se permitir a comparação de entidades públicas similares. O estudo de Galera, Rodríguez e Hernández (2008) debruça-se ainda pela identificação das barreiras para a aplicação normalizada de indicadores de desempenho nos municípios. A nível nacional e com o objectivo de uniformização da informação, no seu estudo Carvalho, Fernandes e Teixeira (2006) sugerem um conjunto de indicadores de gestão com base orçamental e patrimonial (quadros 2 e 3) para o Relatório de Gestão que devem analisar comparativamente os últimos cinco anos. 
Quadro 2 - Indicadores de Gestão Orçamentais

Receita Total / Despesa Total

(Receita Total - Passivo Financeiro) / (Despesa Total - Amortizações)

Receitas Correntes Executadas / Receitas Correntes Orçadas

Receita Total Corrente do ano n / Receita Total Corrente do n-1

Impostos e Taxas / Receitas Correntes

Impostos e Taxas do ano $\mathrm{n} /$ Impostos e Taxas do n-1

Transferências Correntes / Receitas Correntes

Receitas Correntes / Receitas Totais

Despesas Correntes Executadas / Despesas Correntes Orçadas

Despesas com Pessoal / Despesas Correntes

Transferências Correntes Efectuadas / Despesas Correntes

Despesas de Capital Executadas / Despesas de Capital Orçadas

Despesas de Capital / Despesas Totais

Juros Pagos / Receita Corrente

Despesas Correntes do ano n / Despesas Correntes do ano n-1

Serviço da Dívida / Receita Corrente

Dívidas / Receita Corrente

Amortizações de Empréstimo / Empréstimos Utilizados

Empréstimos Utilizados do ano $\mathrm{n} /$ Investimentos do ano $\mathrm{n}$

Investimento do ano $\mathrm{n} /$ Investimento do ano $\mathrm{n}-1$

Fonte: Carvalho, Fernandes e Teixeira (2006, p. 668)

Quadro 3 - Indicadores de Gestão Económicos e/ou Patrimoniais

Imobilizado Líquido do ano $\mathrm{n} /$ Imobilizado Líquido do ano n-1

Amortizações Acumuladas / Activo Bruto

Disponibilidades do ano $\mathrm{n} /$ Disponibilidades do ano $\mathrm{n}-1$

Proveitos diferidos do ano $\mathrm{n} /$ Proveitos Diferidos do ano n-1

Dividas a pagar a curto prazo do ano n / Dívidas a curto prazo do ano n-1

Dívidas a pagar a médio e longo prazo do ano $\mathrm{n} /$ Dívidas a médio e longo prazo do ano n-1

Dívidas a pagar / Activo Líquido

Dívidas a receber do ano $\mathrm{n} /$ Dívidas a receber do ano n-1

Ajustamentos / Dívidas a receber

Resultado Líquido / Fundos Próprios

Proveitos Totais do ano $\mathrm{n} /$ Proveitos Totais do ano $\mathrm{n}-1$

Vendas e Prestações de Serviços do ano n / Vendas e Prestações de Serviços do ano n-1

Proveitos Totais / Custos Totais

Custos Totais do ano $\mathrm{n} /$ Custos Totais do ano $\mathrm{n}-1$

Fornecimentos e Serviços Externos do ano n / Fornecimentos e Serviços Externos do ano n-1

Custos com o Pessoal / Custos Totais

Custos Financeiros do ano n / Custos Financeiros do ano n-1

Fonte: Carvalho, Fernandes e Teixeira (2006, p. 668-669)

Através dos AFMP entre os anos de 2004 e 2007, verificámos que ocorreu uma melhoria na divulgação de indicadores pelos municípios portugueses, apesar do aumento de municípios que em 2007 não apresentaram nenhum indicador.

Tabela 1 - Indicadores Apresentados no Relatório de Gestão dos Municípios Portugueses

\begin{tabular}{|c|c|c|c|c|}
\hline 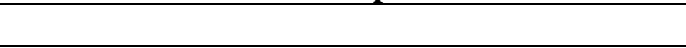 & 2004 & 2005 & 2006 & 2007 \\
\hline Mínimo & 0 & 0 & 0 & 0 \\
\hline $\mathrm{N}^{\circ}$ de municípios com Zero Indicadores & 86 & 69 & 51 & 74 \\
\hline Máximo & 74 & 75 & 64 & 82 \\
\hline $\mathrm{N}^{\circ}$ de municípios com o máximo de Indicadores & n.d & 1 & 1 & 1 \\
\hline Média & 12.5 & 14.5 & 10.7 & 16.9 \\
\hline
\end{tabular}

Fonte: Adaptado de Carvalho et al (2006, 2007, 2008, 2009) 
Relativamente aos tipos de indicadores que têm sido apresentados pelos municípios, constatamos que dão maior importância à informação orçamental, apesar de ter ocorrido um aumento dos indicadores económicos e patrimoniais.

Tabela 2 - Tipo de Indicadores Apresentados no Relatório de Gestão

\begin{tabular}{l|c|c|c}
\hline \multicolumn{1}{c|}{ Tipo } & $\mathbf{2 0 0 4}$ & $\mathbf{2 0 0 5}$ & $\mathbf{2 0 0 6}$ \\
\hline Orçamentais & 333 & 660 & 784 \\
\hline Económico e/ou patrimoniais & 131 & 336 & 433 \\
\hline Outros & 0 & 6 & 15 \\
\hline Total & $\mathbf{4 6 4}$ & $\mathbf{1 0 0 2}$ & $\mathbf{1 2 3 2}$ \\
\hline
\end{tabular}

Fonte: Adaptado de Carvalho et al $(2006,2007,2008)$

Os indicadores orçamentais que mais se repetem no relatório de gestão dos municípios portugueses no ano de 2007 são (CARVALHO et al., 2009, p. 189): (Despesas com Pessoal / Despesas totais); (Despesas com Pessoal / Despesas Correntes); (Despesas com Pessoal / Receitas Correntes); (Receitas Correntes / Receitas Totais); (Receita Total / Despesa Total); (Passivos Financeiros / Investimentos). De salientar, que não foram sugeridos indicadores do subsistema de Contabilidade de Custos, apesar da sua importância para medir a economia, eficiência e eficácia, tendo sido justificado pela fraca implementação deste subsistema de contabilidade, apesar de ser obrigatório.

Neste contexto, estudos de Teixeira et al. (2010) e Mata (2010) verificaram ao nível dos municípios do distrito de Setúbal, que estes continuavam a dedicar pouca atenção a esta temática, dado que ainda nenhum município possuía um sistema de contabilidade de custos totalmente implementado (25\% (3 municípios) já o implementaram parcialmente). Assim, $75 \%$ (9 municípios) ainda não tinham iniciado o processo de implementação deste sistema de contabilidade.

Gonçalves, Correia e Marques (2011) refere que para a Contabilidade Orçamental e Patrimonial existem algumas acções controladoras por parte do Tribunal de Contas mas para o subsistema de contabilidade de Custos não existem mecanismos de enforcement em Portugal. (Gonçalves, Correia e Marques, 2011). O Tribunal de Contas e a Înspecção Geral de Finanças nas suas auditorias têm emitido recomendações às entidades no sentido de estas implementarem este subsistema contabilístico apesar de não ser obrigatório a prestação de contas neste âmbito (GOMES; CARVALHO; FERNANDES, 2009).

\section{ESTUDO EMPÍRICO E ANÁLISE DE RESULTADOS}

\subsection{Caracterização da amostra}

O presente estudo tem como objectivo identificar e avaliar o desempenho dos municípios do distrito de Setúbal, enquanto autarquias locais sujeitas à aplicação do POCAL, bem como analisar a divulgação de indicadores desse desempenho, pelos próprios municípios, no seu Relatório de Gestão. De acordo com Amaral (2002), o município é a autarquia local que visa a prossecução dos interesses comuns da população residente num território delimitado (concelho), através de órgãos eleitos. Os seus principais órgãos são, a Assembleia Municipal, a Câmara Municipal e o Presidente da Câmara. De realçar, que um município pode integrar, com existência autónoma e estrutura própria, empresas mistas e municipais e serviços municipalizados. De acordo com a Direcção Geral das Autarquias Locais (DGAL), existiam no ano de 2010 em Portugal, 308 municípios (278 no continente e 30 nas Regiões Autónomas dos Açores e da Madeira). No âmbito do sector local existiam ainda, 4.259 freguesias, 55 serviços municipalizados e 184 empresas municipais. Segundo Carvalho et al. (2010), os municípios portugueses podem ser repartidos em três dimensões de acordo com o número de habitantes (tabela 3 ). 
Tabela 3 - Municípios Portugueses por Dimensão (número de habitantes)

\begin{tabular}{c|c|c}
\hline Pequenos & Médios & Grandes \\
\hline$\leq 20.000$ hab. & $>20.000$ hab. e $\leq 100.000$ hab. & $>100.000$ hab. \\
\hline 180 Municípios & 105 Municípios & 23 Municípios \\
\hline $58,4 \%$ & $34,1 \%$ & $7,5 \%$ \\
\hline
\end{tabular}

Fonte: Adaptado de Carvalho et al. (2010)

No caso específico do distrito de Setúbal existem 13 municípios e 82 freguesias, que ocupam uma área global de $5.095 \mathrm{Km}^{2}$ (tabela 4). Como referido, no presente estudo só os municípios serão analisados, uma vez que, apenas estas entidades apresentam actualmente contas de acordo com o POCAL. Contudo, no âmbito dos municípios, excluímos as empresas municipais por estarem sujeitas ao Sistema de Normalização Contabilística (SNC) e os serviços municipalizados ou outras instituições, por questões de exequibilidade. A tabela 4 resume as principais características da nossa amostra (número de freguesias, área e número de habitantes) constituída pelos 13 municípios do distrito de Setúbal. Igualmente enquadrámos os municípios pelas categorias dimensionais apresentadas no AFMP de 2008.

Tabela 4 - Caracterização dos Municípios do Distrito de Setúbal

\begin{tabular}{|c|c|c|c|c|c|c|}
\hline \multirow{2}{*}{ Município } & \multirow{2}{*}{ Freguesias } & \multirow{2}{*}{ Áreas $\left(\mathrm{Km}^{2}\right)$} & \multicolumn{4}{|c|}{$\mathrm{N}^{0}$ de Habitantes } \\
\hline & & & 2005 & 2006 & 2007 & 2008 \\
\hline \multicolumn{7}{|c|}{ Grande Dimensão } \\
\hline Seixal & 6 & 96 & 167.839 & 170.626 & 173.406 & 175.837 \\
\hline Almada & 11 & 70 & 165.770 & 166.013 & 166.148 & 166.103 \\
\hline Setúbal & 8 & 172 & 121.384 & 122.554 & 123.584 & 124.459 \\
\hline \multicolumn{7}{|c|}{ Média Dimensão } \\
\hline Barreiro & 8 & 32 & 78.803 & 78.610 & 78.277 & 77.893 \\
\hline Moita & 6 & 55 & 70.638 & 71.019 & 71.374 & 71.596 \\
\hline Palmela & 5 & 463 & 59.399 & 60.619 & 61.758 & 62.820 \\
\hline Sesimbra & 3 & 195 & 46.098 & 48.110 & 50.236 & 52.371 \\
\hline Montijo & 8 & 348 & 40.691 & 40.952 & 41.210 & 41.432 \\
\hline $\begin{array}{l}\text { Santiago do } \\
\text { Cacém }\end{array}$ & 11 & 1.060 & 30.069 & 29.919 & 29.698 & 29.482 \\
\hline \multicolumn{7}{|c|}{ Pequena Dimensão } \\
\hline Alcochete & 3 & 129 & 15.550 & 16.194 & 16.813 & 17.464 \\
\hline Grândola & 5 & 807 & 14.328 & 14.214 & 14.089 & 13.979 \\
\hline Sines & 2 & 203 & 13.645 & 13.674 & 13.681 & 13.681 \\
\hline Alcácer do Sal & 6 & 1.465 & 13.482 & 13.354 & 13.191 & 13.017 \\
\hline Total & 82 & 5.095 & 837.696 & 845.858 & 853.465 & 860.134 \\
\hline
\end{tabular}

Fonte: Adaptado de Carvalho et al. (2010, p. 297-306).

Como podemos observar pela tabela 4, o distrito de Setúbal apresenta municípios com diferentes características e que necessariamente terão influência nas contas e indicadores de cada entidade, como por exemplo, a capacidade de gerar receitas próprias. Assim, por um lado temos municípios como o do Seixal, Almada ou Barreiro com elevada densidade populacional em virtude da sua proximidade à capital Lisboa, e por outro, temos Santiago do Cacém, Alcácer do Sal ou Grândola como municípios da região do Alentejo caracterizada por uma maior interioridade e baixa densidade populacional. No ponto intermédio temos o aglomerado populacional do concelho de Setúbal, Palmela e Sesimbra.

Por outro lado verificamos, que nos quatro anos em análise, o número de habitantes do distrito de Setúbal cresceu anualmente, chegando em 2008, aos 860.134 habitantes. Todavia, esse crescimento não foi acompanhado nos municípios do Barreiro, Santiago do Cacém, Grândola e Alcácer do Sal onde houve de ano para ano, um decréscimo do número de habitantes. Através do AFMP de 2008, podemos constatar ainda que o distrito de Setúbal é dos maiores do país, sendo o $4^{\circ}$ em população residente e o $6^{\circ} \mathrm{em}$ densidade populacional. 
Acresce ainda o facto de juntamente com Lisboa e Faro ser o distrito com maior crescimento populacional nesse ano.

\subsection{Metodologia}

Para a concretização dos três objectivos de estudo nomeadamente, a análise da informação constante no AFMP (referência nacional) identificando o desempenho de municípios do distrito de Setúbal, a criação de um ranking de desempenho específico para o distrito e a análise à divulgação de indicadores nos Relatórios de Gestão, a metodologia assentou essencialmente na análise de conteúdo e tratamento da informação recorrendo a estatística descritiva.

Se a primeira questão de investigação se centrou na análise de conteúdo do AFMP publicado em 2010 e relativo ao ano de 2008, para a segunda e terceira questão foi necessário uma análise de conteúdo aos Relatórios e Contas de 2008 e parcialmente aos de 2007. Os Relatórios e Contas foram obtidos nos respectivos sítios institucionais na Internet, onde os municípios devem publicitar os seus documentos de prestação de contas de acordo com o n. ${ }^{\circ}$ 2 do artigo $49 .^{\circ}$ da Lei das Finanças Locais. Contudo, não foi possível recolher todos os documentos de prestação de contas, verificando-se que 3 dos municípios não cumpriam com o dever completo de publicitação. Para algumas das questões de investigação, foi possível suprimir a falta dos Relatórios e Contas através de informação obtida por endereço electrónico, permanecendo contudo alguns casos de falta de informação.

Mais especificamente para a questão relativa à elaboração de um ranking global de desempenho dos municípios do distrito de Setúbal, a metodologia de construção do ranking assentou na metodologia utilizada no AFMP, o qual utilizou quinze indicadores que segundo os autores (CARVALHO et al., 2010), melhor avaliam a gestão financeira, económica, patrimonial e orçamental dos municípios (tabela 5). O apuramento do ranking global no AFMP foi efectuado, considerando para cada indicador a atribuição de uma pontuação de 10 pontos aos 25 melhores municípios, 9 pontos do $26^{\circ}$ ao $50^{\circ}, 8$ pontos de $51^{\circ}$ ao $75^{\circ}$, e assim sucessivamente. Desta forma foram pontuados 250 municípios por cada indicador. Por outro lado, alguns indicadores tiveram uma ponderação de 2 em virtude da sua importância no âmbito das exigências da nova Lei das Finanças Locais. Posteriormente e com base nos pressupostos enunciados, foram elaborados 3 rankings:

- Ranking Global dos 10 melhores municípios de grande dimensão, em termos de eficiência financeira;

- Ranking Global dos 20 melhores municípios de média dimensão, em termos de eficiência financeira;

- Ranking Global dos 30 melhores municípios de pequena dimensão, em termos de eficiência financeira.

O ranking que desenvolvemos para o distrito de Setúbal, assenta na metodologia do AFMP, embora ajustado devido a limitações no número de municípios (11) e número de indicadores (13), em virtude de tal como referido anteriormente, não ter sido possível a obtenção de todos os Relatórios e Contas. As diferenças entre a metodologia base (AFMP) e a do ranking elaborado no presente estudo são detalhadas posteriormente em secção própria (ponto 4.3.2).

\subsection{Ranking de desempenho dos municípios do distrito de Setúbal}

Sendo o AMFP, a referência nacional na avaliação de desempenho dos municípios e um documento que permite a análise dessas entidades através de rankings dos quais pode constar informação sobre o distrito de Setúbal, o primeiro objectivo de investigação prende-se com a identificação de informação orçamental e patrimonial disponibilizada para cada 
município do distrito. Posteriormente, e de forma a melhorar a análise será elaborado e apresentado um ranking global específico para os municípios do distrito de Setúbal.

Tabela 5 - Indicadores para o Ranking Global

\begin{tabular}{c|l|l|c}
\hline $\mathbf{N}^{\mathbf{0}}$ & Indicador & Fonte de Informação & Peso \\
\hline 1 & Dívidas a terceiros por habitante & Balanço & 2 \\
\hline 2 & Liquidez & Balanço & 2 \\
\hline 3 & Endividamento líquido por habitante & Balanço & 2 \\
\hline 4 & Resultado operacional por habitante & Demonstração Resultados & 1 \\
\hline 5 & Peso dos custos com pessoal nos custos operacionais & Demonstração Resultados & 1 \\
\hline 6 & Diminuição das dívidas de curto prazo & Balanço & 1 \\
\hline 7 & Diminuição dos passivos financeiros & Balanço & 2 \\
\hline 8 & $\begin{array}{l}\text { Grau de execução da receita líquida relativamente às } \\
\text { despesas comprometidas }\end{array}$ & Mapas Controlo Orçamental & 1 \\
\hline 9 & Prazo médio de pagamentos & DGAL & 1 \\
\hline 10 & Saldo primário na óptica dos compromissos & Mapas Controlo Orçamental & 1 \\
\hline 11 & Índice de endividamento líquido & $\begin{array}{l}\text { Balanço e Mapas Controlo } \\
\text { Orçamental }\end{array}$ & 1 \\
\hline 12 & Diminuição do endividamento líquido & Balanço & 2 \\
\hline 13 & Peso das dívidas a instituições de crédito nas receitas n-1 & Balanço e Mapas Controlo & 1 \\
& & Orçamental & \\
\hline 14 & Peso das dívidas a fornecedores nas receitas n-1 & $\begin{array}{l}\text { Balanço e Mapas Controlo } \\
\text { Orçamental }\end{array}$ & 1 \\
\hline 15 & $\begin{array}{l}\text { Grau de execução da receita cobrada relativamente à } \\
\text { despesa paga }\end{array}$ & Mapas Controlo Orçamental & 1 \\
\hline
\end{tabular}

Fonte: Adaptado de Carvalho et al. (2010, p. 214-215).

\subsubsection{Análise de desempenho aos municípios do distrito de setúbal conforme informação constante no AFMP}

No que toca à informação relativa à execução orçamental da receita, o AFMP mostra que a nível nacional, que os municípios com maior peso de receitas próprias são essencialmente do litoral do país e de maior dimensão, o que se traduz igualmente numa maior capacidade de obtenção de receitas provenientes de impostos. Assim, sendo o distrito de Setúbal, uma região de litoral e em parte com municípios de elevada densidade populacional, não é de estranhar que 9 dos 13 municípios figurem entre os 50 nacionais com maior peso de receitas próprias (tabela 6). O município de Sesimbra é o melhor posicionado no distrito ( $6^{\mathrm{a}}$ posição no ranking nacional) com uma independência financeira (peso das receitas próprias nas receitas totais) de $77 \%$. De referir ainda que nenhum dos municípios figura nos $50 \mathrm{com}$ menor independência financeira.

Tabela 6 - Municípios com maior Independência Financeira em 2008

\begin{tabular}{c|c|c|c|c}
\hline Posição & Município & Dimensão & \% (2008) & \% (2007) \\
\hline 6 & Sesimbra & M & $81 \%$ & $85 \%$ \\
\hline 9 & Setúbal & G & $77 \%$ & $74 \%$ \\
\hline 14 & Palmela & M & $74 \%$ & $78 \%$ \\
\hline 17 & Almada & G & $72 \%$ & $76 \%$ \\
\hline 18 & Alcochete & P & $71 \%$ & $71 \%$ \\
\hline 19 & Montijo & M & $70 \%$ & $67 \%$ \\
\hline 21 & Seixal & G & $70 \%$ & $82 \%$ \\
\hline 41 & Sines & P & $64 \%$ & $46 \%$ \\
\hline
\end{tabular}

Fonte: Adaptado de Carvalho et al. (2010, p. 57-58).

Dentro da análise das receitas próprias, os impostos e taxas são as receitas mais 
relevantes, sendo normal que os municípios citados no quadro anterior estejam quase todos no ranking dos 35 municípios com maior peso destas receitas na sua estrutura total de receita.

Tabela 7 - Municípios com maior Peso de Receitas Provenientes de Impostos e Taxas em 2008

\begin{tabular}{c|c|c|c}
\hline Posição & Município & Dimensão & \% \\
\hline 9 & Montijo & $\mathrm{M}$ & $59,7 \%$ \\
\hline 10 & Palmela & $\mathrm{M}$ & $59,1 \%$ \\
\hline 15 & Setúbal & $\mathrm{G}$ & $56,8 \%$ \\
\hline 18 & Almada & $\mathrm{P}$ & $54,6 \%$ \\
\hline 20 & Alcochete & $\mathrm{G}$ & $53,9 \%$ \\
\hline 21 & Seixal & $\mathrm{M}$ & $53,6 \%$ \\
\hline 26 & Sesimbra & & $50,1 \%$ \\
\hline
\end{tabular}

Fonte: Adaptado de Carvalho et al. (2010, p. 68-69).

Outro aspecto importante consiste na análise da receita proveniente do recurso a crédito. O AFMP faz referência aos municípios nacionais com menor peso (perto de 0\%) de receitas creditícias, onde podemos encontrar Alcácer do Sal, Alcochete e Setúbal. Já nos 35 municípios nacionais com maior grau de execução (receita cobrada face ao valor orçamentado) encontramos em $2^{\mathrm{a}}$ lugar Palmela (100,2\%), $13^{\circ}$ Almada $(91,7 \%), 15^{\circ}$ Grândola $(90,7 \%)$ e $16^{\circ}$ Moita $(90,1 \%)$. Quanto aos 35 municípios com menor grau de execução, apenas consta Sines com um grau de execução de 44,0\%.

Ao nível do orçamento de despesa, as despesas com pessoal são aquelas que maior peso têm no total da despesa dos municípios nacionais. Desta forma torna-se interessante verificar a situação dos municípios do distrito de Setúbal quanto a esta rubrica. São 7 os municípios que figuram nos 35 com maior peso das despesas com pessoal, sendo inclusive Alcochete a entidade que lidera o ranking com 58,4\% da sua despesa total a ser aplicada na rubrica de pessoal. Já no ranking dos municípios com menor peso, não existe referência a qualquer município do distrito de Setúbal.

Tabela 8 - Municípios com maior Peso das Despesas com Pessoal nas Despesas Totais

\begin{tabular}{|c|c|c|c|c|}
\hline \multicolumn{4}{|c|}{2008} & \multirow{2}{*}{$\begin{array}{c}2007 \\
\text { Posição }\end{array}$} \\
\hline Posição & Município & Dimensão & $\%$ & \\
\hline 1 & Alcochete & $\mathrm{P}$ & $58,4 \%$ & 3 \\
\hline 4 & Moita & $\mathrm{M}$ & $51,6 \%$ & 9 \\
\hline 7 & Santiago do Cacém & $\mathrm{M}$ & $49,0 \%$ & 20 \\
\hline 13 & Sesimbra & $\mathrm{M}$ & $46,2 \%$ & 28 \\
\hline 29 & Barreiro & $\mathrm{M}$ & $42,2 \%$ & 18 \\
\hline 31 & Montijo & $\mathrm{M}$ & $41,9 \%$ & 26 \\
\hline 33 & Setúbal & $\mathrm{G}$ & $40,9 \%$ & 12 \\
\hline
\end{tabular}

Fonte: Adaptado de Carvalho et al. (2010, p. 100)

Sobre as restantes rubricas de despesa não são disponibilizados rankings, pelo que não foi possível verificar a situação dos municípios de Setúbal a esse nível. Contudo da análise global pode-se constatar que a autarquia de Sines figura igualmente nos municípios com menor rácio entre as receitas liquidadas e as receitas previstas, com cerca de 47,4\%, manifestamente abaixo da execução da despesa comprometida, de 77,3\%. Este desequilíbrio é bastante preocupante, sendo um indício claro do agravamento do endividamento.

Ao nível da análise da informação do Balanço, as rubricas de Activo e Fundos Próprios são apresentados apenas na perspectiva nacional, o que demonstra a insuficiência do AFMP em representar o desempenho detalhado dos municípios do distrito de Setúbal. Contudo, para o passivo o AFMP já estabelece rankings, podendo verificar-se que ao nível dos municípios nacionais com menor Passivo Exigível em 2008, apenas Alcácer do Sal figura no ranking (posição 20 e um passivo de cerca de 2.213 mil euros). No entanto, este ranking é 
influenciado pela dimensão dos próprios municípios sendo composto quase em exclusivo por entidades de pequena dimensão. Assim, a análise é apresentada posteriormente por dimensão dos municípios e por número de habitantes. No ranking dos municípios de pequena dimensão com menor passivo exigível, podemos confirmar que Alcácer do Sal pouco altera a sua posição $\left(19^{\circ}\right)$, sendo que nenhum município do distrito Setúbal de média dimensão figura nesse ranking. Já na análise dos municípios de grande dimensão com menor passivo exigível podemos verificar que Almada é o melhor cotado com 41.496 mil euros e ocupando a $3^{\mathrm{a}}$ posição do ranking. Numa análise por habitante podemos constatar que Palmela é o município melhor cotado. Por outro lado, a melhoria a este nível no município de Almada fez com que passasse a constar no ranking de 2008.

Tabela 9 - Municípios com menor Passivo Exigível por Habitante em 2008

\begin{tabular}{c|c|c|c}
\hline Posição & Município & Dimensão & Dívida por Habitante \\
\hline 9 & Palmela & $\mathrm{M}$ & $169,07 €$ \\
\hline 10 & Alcácer do Sal & $\mathrm{P}$ & $170,03 €$ \\
\hline 32 & Almada & $\mathrm{G}$ & $249,82 €$ \\
\hline
\end{tabular}

Fonte: Adaptado de Carvalho et al. (2010, p. 135)

No ranking dos municípios com maior passivo exigível encontra-mos na $15^{\mathrm{a}}$ posição, Setúbal com 75.726 mil euros e na $22^{a}$ posição, Seixal com 60.057 mil euros. Contudo, o município de Setúbal tem vindo a reduzir o seu passivo exigível, sendo que representou a nível nacional $4^{a}$ maior redução de passivo exigível de 2007 para 2008. Igualmente Almada sofreu uma redução no seu passivo exigível. No sentido contrário aparecem os municípios do Seixal e de Sesimbra que no ranking nacional ocupam as posições 11 e 21 ao registarem os maiores aumentos dos seus passivos exigíveis face a 2007.

O AFMP apresenta ainda uma análise de liquidez e no âmbito da Lei das Finanças Locais uma análise de endividamento líquido. $\mathrm{Na}$ sua grande maioria os municípios portugueses sofrem de falta de liquidez sendo que dos 308 municípios nacionais, apenas 36\% apresentam liquidez positiva. A tabela 10 identifica os municípios do distrito de Setúbal que figuram no ranking dos 35 municípios com maior liquidez.

Tabela 10 - Municípios com maior Liquidez

\begin{tabular}{c|c|c|c|c}
\hline Posição & Município & Dimensão & Ranking 2008 & Ranking 2007 \\
\hline 2 & Almada & G & 51.306 .987 & 59.543 .702 \\
\hline 13 & Seixal & G & 13.480 .975 & 9.686 .966 \\
\hline 22 & Setúbal & G & 4.993 .852 & - \\
\hline 23 & Palmela & M & 4.388 .901 & 4.305 .539 \\
\hline
\end{tabular}

Fonte: Adaptado de Carvalho et al. (2010, p. 138-139)

No ranking dos 35 municípios com menor liquidez, surge apenas o município de Sines na $24^{\mathrm{a}}$ posição e com uma liquidez negativa de 11.187 mil euros. Quanto ao endividamento líquido, dos 35 municípios sem (valores negativos) ou com baixo endividamento podemos encontrar na $2^{\mathrm{a}}$ posição Almada (-13.887 mil euros) e Alcácer do Sal na $27^{\mathrm{a}}$ posição com um valor de 388 mil euros. Os municípios anteriormente mencionados surgem igualmente no ranking dos municípios com menor índice de endividamento líquido em relação às receitas do ano anterior, ranking que inclui ainda o município de Palmela. Dos 35 municípios com maior endividamento, apesar da redução em $10 \%$ face ao ano de 2007, encontra-se Setúbal com 59.242 mil euros.

Noutros indicadores é de salientar, que Alcácer do Sal é o único a constar no ranking dos 25 municípios com menor peso da dívida à banca sobre as receitas cobradas em n-1, apresentando um rácio de $11 \%$. No ranking contrário surge Moita com 140,6\% e Setúbal com 139,7\%. Dos municípios de pequena dimensão com um valor de dívidas a fornecedores superior a $50 \%$ das receitas totais, encontramos na $26^{a}$ posição Sines com um índice de $67 \%$, 
resultante de 15.000 mil euros de dívidas a fornecedores e 22.262 mil euros de receitas cobradas em 2007. Já no ranking dos 35 municípios com menor índice de dívida a fornecedores em 2008, face às receitas totais de 2007, surge na $34^{\mathrm{a}}$ posição Palmela com $4,6 \%$.

Ao nível da análise económica defende Carvalho et al. (2010, p. 145), que o "resultado económico ainda não pode ser visto como o principal indicador de análise comparativa da eficácia dos municípios". Justificando pelo facto de os municípios não utilizarem critérios de valorimetria idênticos, nem reconhecem no Activo todo o imobilizado e nas Demonstrações de Resultados as respectivas amortizações, bem como, não cumprirem algumas das regras do POCAL. Dos 25 municípios com maior resultado económico negativo, surgem 2 do distrito de Setúbal, ou seja, Seixal (-4.927 mil euros) e Setúbal (-3.096 mil euros). De salientar, o município de Almada com o $4^{\circ}$ maior resultado económico em 2008, com o montante de 12.254 mil euros.

Na tabela 11 apresenta-se os principais dados económicos dos municípios do distrito de Setúbal, bem como o valor do passivo exigível. Quando analisados os resultados operacionais dos municípios do distrito de Setúbal, que representam 3,1\% dos proveitos totais, verificamos que cinco (Alcochete, Montijo, Palmela, Santiago do Cacém e Sesimbra) apresentam resultados operacionais negativos. Por outro lado, se essa análise se situar ao nível dos resultados do exercício, que representam $1,3 \%$ do total dos proveitos, os municípios com valores negativos continuam a ser cinco, mas apenas três são coincidentes, sendo que os municípios de Sesimbra e Alcochete trocam com os municípios do Seixal e Setúbal.

Tabela 11 - Dados Económicos dos Municípios do Distrito de Setúbal (em euros)

\begin{tabular}{l|r|r|r|r|r}
\multicolumn{1}{c|}{ Municípios } & $\begin{array}{c}\text { Total de } \\
\text { Custos }\end{array}$ & $\begin{array}{c}\text { Total de } \\
\text { Proveitos }\end{array}$ & $\begin{array}{c}\text { Resultado } \\
\text { Operacional }\end{array}$ & $\begin{array}{c}\text { Resultado } \\
\text { Exercício }\end{array}$ & $\begin{array}{c}\text { Passivo } \\
\text { Exigível }\end{array}$ \\
\hline Alcácer do Sal & 15.925 .879 & 16.350 .389 & 1.016 .391 & 424.510 & 2.213 .315 \\
\hline Alcochete & 12.515 .348 & 12.853 .969 & -281.751 & 338.621 & 6.330 .802 \\
\hline Almada & 70.594 .013 & 82.848 .468 & 6.256 .060 & 12.254 .455 & 41.496 .230 \\
\hline Barreiro & 36.267 .381 & 37.693 .909 & 5.233 .611 & 1.426 .528 & 34.443 .357 \\
\hline Grândola & 15.582 .689 & 19.206 .364 & 3.165 .349 & 3.623 .675 & 12.528 .040 \\
\hline Moita & 26.529 .745 & 28.230 .016 & 2.706 .025 & 1.700 .271 & 31.456 .317 \\
\hline Montijo & 30.054 .652 & 27.846 .227 & -243.392 & -2.208 .425 & 16.898 .370 \\
\hline Palmela & 44.778 .546 & 42.492 .058 & -2.542 .020 & -2.286 .488 & 35.971 .885 \\
\hline Santiago Cacém & 21.803 .345 & 21.592 .038 & -559.360 & -211.307 & 19.241 .384 \\
\hline Seixal & 90.088 .159 & 85.161 .374 & 379.880 & -4.926 .785 & 60.057 .433 \\
\hline Sesimbra & 41.718 .627 & 43.036 .438 & -3.459 .056 & 1.317 .811 & 24.204 .440 \\
\hline Setúbal & 73.500 .118 & 70.404 .106 & 1.969 .560 & -3.096 .012 & 75.726 .187 \\
\hline Sines & 19.066 .098 & 20.838 .247 & 2.269 .687 & 1.772 .149 & 22.613 .475 \\
\hline Total dos Municípios do & 498.424 .600 & 508.553 .603 & 15.910 .984 & 6.584 .705 & 383.181 .235 \\
Distrito de Setúbal & & & & &
\end{tabular}

Fonte: Adaptado de Carvalho et al. (2010, p. 194-212)

No final do AFMP é apresentado um ranking global de desempenho dos municípios construído de acordo com os indicadores da tabela 8 e em função da metodologia referenciada anteriormente no ponto 4.2. Os rankings nacionais apurados evidenciam que apenas um município do distrito de Setúbal figura em cada ranking. Nos de grande dimensão, Almada ocupa a $5^{\text {a }}$ posição, nos de média dimensão Palmela é o $20^{\circ}$ e nos de pequena dimensão Alcácer do Sal é o $19^{\circ}$. Assim e em função de a informação disponibilizada não identificar o ranking de todos os municípios do distrito de Setúbal, o nosso segundo objectivo de investigação, compreendeu a obtenção de um ranking global exclusivo do distrito.

\subsubsection{Elaboração de um Ranking de Desempenho para os Municípios do Distrito de Setúbal}

A elaboração de um ranking global para os municípios do distrito utilizando a 
metodologia do AFMP, implicou o cálculo de cada um dos indicadores para cada município. Para tal foi necessário recorrer à análise da informação orçamental e contabilística constante nos Relatórios e Contas de 2008 dos respectivos municípios. Para 3 dos indicadores foi necessário, ainda, analisar a informação orçamental do ano de 2007 e para o Prazo Médio de Pagamento (PMP) a fonte seguida foi a informação constante no sítio da internet da DGAL. Conforme referido no ponto da metodologia, nem todos os municípios disponibilizaram no seu sítio na internet os Relatórios e Contas. Dos 13 municípios, 11 disponibilizaram o Relatório e Contas de 2008 e apenas 9, o Relatório e Contas de 2007.

Esta situação conduziu a algumas limitações no apuramento da informação para cálculo dos indicadores do ranking, a qual se tentou suprimir através de pedido formalizado por e-mail para os municípios em questão. Após este procedimento foi possível ter informação completa sobre o ano de 2008 para 12 entidades e sobre 2007 para 10 entidades. Esta limitação para os indicadores que têm por base informação do ano de 2007 foi parcialmente suprimidas, pois foi possível em alguns casos, obter o valor desse indicador directamente do AFMP.

Contudo, e face às limitações que subsistiam foi decidido retirar da construção do ranking global o município de Alcochete e Palmela, visto não ter sido possível a obtenção da totalidade de informação necessária sobre o ano de 2008. Optou-se também, pela exclusão de dois indicadores referenciados na tabela 5 que tinham por base o ano de 2007 (índice de endividamento público e o peso das dívidas a fornecedores nas receitas n-1), visto não estarem totalmente disponíveis em 2 dos municípios. Assim, a construção do ranking global assenta na classificação individual de 11 municípios do distrito de Setúbal em 13 indicadores. Os rankings apresentados individualmente foram ajustados, considerando todos os municípios à excepção de Alcochete e Palmela.

Para a classificação de desempenho em cada indicador, seguiu-se a mesma ponderação considerada no AFMP, sendo que a pontuação é obtida de forma inversa à classificação em cada indicador. Por exemplo, Alcácer do Sal é o $1^{\circ}$ no ranking de dívidas a terceiros por habitante (município de Palmela foi excluído), obtendo assim 11 pontos. Como este indicador é ponderado a 2 , os pontos considerados para o ranking global são 22 . O último dos 11 municípios representa 1 ponto, ou 2 pontos no caso de o indicador ter ponderação 2 . A tabela 12 exemplifica a hierarquização e pontuação referente ao desempenho de cada município no indicador "Grau da Execução da Receita Liquidada relativamente à Despesa Comprometida".

Tabela 12 - Ranking para o indicador: Grau de execução da receita liquidada relativamente à despesa comprometida

\begin{tabular}{c|c|c|c|c}
\hline Ranking & Municípios & Dimensão & \% & Pontos (Peso 1) \\
\hline 1 & Grândola & $\mathrm{P}$ & 105,2 & 11 \\
\hline 2 & Almada & $\mathrm{G}$ & 98,6 & 10 \\
\hline 3 & Moita & $\mathrm{M}$ & 97,7 & 9 \\
\hline 4 & Alcácer do Sal & $\mathrm{P}$ & 89,3 & 8 \\
\hline 5 & Barreiro & $\mathrm{M}$ & 87,2 & 7 \\
\hline 6 & Montijo & $\mathrm{M}$ & 86,6 & 6 \\
\hline 7 & Seixal & $\mathrm{G}$ & 83,3 & 5 \\
\hline 8 & Setúbal & $\mathrm{G}$ & 76,6 & 3 \\
\hline 9 & Santiago do Cacém & $\mathrm{M}$ & 75,4 & 2 \\
\hline 10 & Sesimbra & $\mathrm{M}$ & 75,1 & 1 \\
\hline 11 & Sines & $\mathrm{P}$ & 58,5 & \\
\hline
\end{tabular}

Fonte: Elaboração Própria

No final a pontuação global é obtida somando a pontuação individual e ponderada de cada município em cada indicador, permitindo a hierarquização comparativa de desempenho dos municípios do distrito de Setúbal apresentada nas tabelas 13 e 14, sendo que nesta última os municípios estão enquadrados pela sua dimensão. De uma forma geral o resultado destas 
tabelas é consistente com a informação prestada no AFMP para os melhores municípios a nível nacional.

Pela tabela 13, podemos observar que Alcácer do Sal é o município que lidera o ranking, seguido de Almada, sendo juntamente com Palmela (não disponível no nosso estudo) os únicos a figurar entre os melhores colocados no AFMP. Pela análise individual efectuada a cada indicador, verificámos que estes municípios têm um equilíbrio financeiro muito superior aos restantes, destacando-se nos diversos indicadores de nível endividamento e cumprimento da dívida. Para além disso, têm uma posição muito acima da média nos indicadores de análise económica e nos de execução orçamental. Apenas no indicador de diminuição da dívida de curto prazo, Alcácer do Sal se encontra na parte inferior do ranking, assim como, o município de Almada na diminuição do endividamento líquido. Contudo, esta situação até pode ser encarada como normal visto a sua saúde financeira estrutural. No $3^{\circ}$ lugar, o município de Grândola destaca-se pela performance orçamental e pela posição nos indicadores económicos.

No fim do ranking encontramos os municípios de Sines $\left(9^{\circ}\right)$, Moita $\left(10^{\circ}\right)$ e por último Santiago do Cacém $\left(11^{\circ}\right)$. A posição do município de Sines é explicada pelo elevado nível de dívida e uma execução orçamental desequilibrada, sendo contudo atenuada pelo comportamento positivo na diminuição do endividamento líquido e dos passivos financeiros e pela sua posição nos indicadores económicos. Já o município da Moita, é essencialmente penalizado pelo aumento verificado no valor dos passivos financeiros e, consequentemente, no aumento do endividamento líquido. Esta situação gerou igualmente um maior desequilíbrio em relação ao nível de receita (tendo por base o ano anterior). Por fim, o município de Santiago do Cacém é aquele com pior situação tendo em conta os diversos rankings individuais considerados para o ranking global. A liquidez, o nível de endividamento, os indicadores económicos e a desequilibrada situação da execução orçamental, são os factores que mais contribuem para a colocação de Santiago do Cacém no último lugar do ranking do distrito.

Tabela 13 - Ranking Global dos Municípios do Distrito de Setúbal em 2008

\begin{tabular}{c|c|c|c}
\hline Ranking & Municípios & Dimensão & Pontuação \\
\hline 1 & Alcácer do Sal & $\mathrm{P}$ & 159 \\
\hline 2 & Almada & $\mathrm{G}$ & 149 \\
\hline 3 & Grândola & $\mathrm{P}$ & 131 \\
\hline 4 & Montijo & $\mathrm{M}$ & 107 \\
\hline 5 & Setúbal & $\mathrm{G}$ & 105 \\
\hline 6 & Barreiro & $\mathrm{G}$ & 101 \\
\hline 7 & Seixal & $\mathrm{M}$ & 89 \\
\hline 8 & Sesimbra & $\mathrm{P}$ & 85 \\
\hline 9 & Sines & $\mathrm{M}$ & 81 \\
\hline 10 & Moita & $\mathrm{M}$ & 78 \\
\hline 11 & Santiago do Cacém & $\mathrm{M}$ & n.d \\
\hline- & Palmela & $\mathrm{P}$ & n.d \\
\hline
\end{tabular}

Fonte: Elaboração Própria

Analisando o ranking por dimensão dos municípios verificamos a excelente posição dos pequenos municípios, à excepção de Sines. Os municípios de grande dimensão têm igualmente posição de destaque, sendo contudo importante salientar que o município de Palmela, considerado de média dimensão, ao ser incluído no ranking global poderia ter modificado ligeiramente esta tendência, visto estar entre os três melhores do distrito a nível nacional. Sem a inclusão de Palmela, o município do Montijo é o melhor cotado nos de média dimensão, sendo Almada o primeiro nos de grande dimensão e obviamente Alcácer do Sal nos municípios de pequena dimensão. 
Tabela 14 - Ranking dos Municípios do Distrito de Setúbal por dimensão

\begin{tabular}{|c|c|c|}
\hline Ranking & Municípios & Pontuação \\
\hline \multicolumn{3}{|c|}{ Grande Dimensão } \\
\hline 1 & Almada & 149 \\
\hline 2 & Setúbal & 105 \\
\hline 3 & Seixal & 101 \\
\hline \multicolumn{3}{|c|}{ Média Dimensão } \\
\hline 1 & Montijo & 107 \\
\hline 2 & Barreiro & 103 \\
\hline 3 & Sesimbra & 89 \\
\hline 4 & Moita & 81 \\
\hline 5 & Santiago do Cacém & 78 \\
\hline- & Palmela & n.d \\
\hline \multicolumn{3}{|c|}{ Pequena Dimensão } \\
\hline 1 & Alcácer do Sal & 159 \\
\hline 2 & Grândola & 131 \\
\hline 3 & Sines & 85 \\
\hline- & Alcochete & n.d \\
\hline
\end{tabular}

Fonte: Elaboração Própria

Apesar de a construção do ranking permitir uma ideia sobre a avaliação de desempenho dos municípios do distrito, este parece-nos pelas razões já apontadas anteriormente, carecer de indicadores de gestão retirados do Sistema de Contabilidade de Custos e mais concretos na medição da economia, eficiência e eficácia das autarquias na condução das suas actividades.

\subsection{Análise dos indicadores divulgados no relatório de gestão}

Neste objectivo de investigação pretendemos analisar a informação prestada através de indicadores no Relatório de Gestão dos municípios do distrito de Setúbal, nomeadamente de 10 municípios que disponibilizam o documento de prestação de contas no seu sítio de internet, contando o número e classificando o tipo de indicador reportado. Os indicadores observados foram classificados em indicadores orçamentais e indicadores económico e/ou patrimoniais. Posteriormente verificámos o número de vezes que cada indicador era apresentado pelos municípios.

Desta forma, os resultados evidenciaram que 3 municípios não apresentam nenhum indicador, sendo que os restantes 7 municípios apresentam no total 159 indicadores. $\mathrm{O}$ máximo de indicadores apresentados por um município é de 45. Dos 159 indicadores apresentados, 115 são do tipo orçamental $(72 \%)$ e 44 do tipo económico e/ou patrimonial (28\%). Constatámos que 2 municípios reportam uma análise comparativa dos últimos 5 anos, tal como proposto por Carvalho, Fernandes e Teixeira (2006) e os restantes municípios efectuam uma análise com 3 anos (4 municípios) e 2 anos (1 município). Pela tabela 15 podemos observar os indicadores orçamentais que mais se repetem nos municípios do distrito de Setúbal em 2008.

Tabela 15 - Indicadores Orçamentais mais repetidos pelos Municípios do Distrito de Setúbal

\begin{tabular}{c|c}
\hline Passivos Financeiros / Investimento & 3 \\
\hline Receitas Correntes / Receitas Totais & 3 \\
\hline Receitas de Capital / Receitas Totais & 3 \\
\hline Investimentos / Despesas de Capital & 3 \\
\hline Investimentos / Despesas Totais & 3 \\
\hline Despesas com Pessoal / Despesas Correntes & 3 \\
\hline
\end{tabular}

Fonte: Elaboração Própria 
Face aos indicadores tipo orçamentais mais divulgados pelos municípios portugueses constatamos que os municípios de Setúbal, também evidenciam os indicadores "Passivos Financeiros / Investimentos" e "Despesas com Pessoal / Despesas Correntes" (tabela 16). A utilização de indicadores relacionados com as despesas com pessoal é justificada por ser a despesa mais representativa na globalidade da despesa autárquica e em particular nos municípios do distrito de Setúbal. Importa salientar, que de acordo com o Decreto-Lei $\mathrm{n}^{\circ} 116 / 84$, de 6 de Abril, com as alterações introduzidas pelo Decreto-Lei ${ }^{\circ} 44 / 85$, de 13 de Setembro, as despesas com o pessoal do quadro não podem exceder $60 \%$ das receitas correntes do ano anterior e as despesas totais com o pessoal em qualquer outra situação não podem exceder $25 \%$. Verificámos que apenas 2 municípios apresentam a análise dos limites das despesas com o pessoal.

Tabela 16 - Indicadores Económicos e/ou Patrimoniais mais repetidos pelos Municípios do Distrito de Setúbal

\begin{tabular}{|c|c|}
\hline Capital Próprio / Activo Líquido Total & 4 \\
\hline Fundos Próprios / Passivo Total & 4 \\
\hline Resultado Líquido / Fundos Próprios & 3 \\
\hline (Disponibilidades + Divididas de 3 ${ }^{\circ}$ curto prazo + Existências + Títulos negociáveis) / Dívidas a 3 ${ }^{\circ}$ curto prazo & 2 \\
\hline Disponibilidades / Exigível de curto prazo & 2 \\
\hline Disponibilidades do ano n / Disponibilidades do ano n-1 & 2 \\
\hline Eívidas a pagar a curto prazo do ano n / Dívidas a pagar a curto prazo do ano n-1 & 2 \\
\hline Empréstimos Médio Longo Prazo / Passivo & 2 \\
\hline Imobilizado Líquido do ano n / Imobilizado Líquido do ano n-1 & 2 \\
\hline Resultado Líquido / Activo & 2 \\
\hline Resultado Líquido + Amortizações e variações de provisões & 2 \\
\hline
\end{tabular}

Fonte: Elaboração Própria.

Face aos indicadores tipo económico e/ou patrimoniais mais reportados pelos municípios portugueses constatamos que os municípios de Setúbal, também destacam os indicadores "Capital Próprio / Activo Líquido Total" e "Fundos Próprios / Passivo Total". Verificamos ainda uma preocupação em apresentar indicadores sobre a liquidez geral. Destacam-se ainda os indicadores "Resultado Líquido / Fundos Próprios" e "Resultado líquido / Activo", embora de acordo com o AFMP de 2008, as referidas insuficiências na aplicação das regras contabilísticas do POCAL, faça com estes indicadores não sejam ainda vistos como indicadores de excelência para avaliar o desempenho dos municípios.

Convém ainda referir que foi identificada a utilização de indicadores idênticos para a avaliação das mesmas situações, mas que apresentam designações diferentes, o que reflecte a ausência de normalização de indicadores e de uma uniformização de análise por cada município.

\section{CONCLUSÕES}

O objectivo do presente documento visou a identificação dos indicadores que estão a ser utilizados para evidenciar o desempenho dos municípios, com especial incidência para a informação prestada pelos municípios do distrito de Setúbal. Procurou-se assim analisar a informação constante dos Relatórios e Contas destas entidades, utilizando os dados já trabalhados no AFMP. Este foi o documento base para a realização dos diversos objectivos específicos do estudo, sendo o ponto de partida para a elaboração de um ranking de desempenho para os municípios da amostra e para a análise da divulgação de indicadores no Relatório de Gestão. Os principais resultados do estudo podem ser sintetizados da seguinte forma:

- Ausência de indicadores assentes na contabilidade de custos, essencialmente em virtude da sua baixa implementação, facto extensível à realidade nacional; 
- A informação tratada no AFMP é apresentada numa perspectiva orçamental e patrimonial constando informação sobre os municípios do distrito de Setúbal, embora dispersa e inserida num contexto nacional e de apresentação de rankings para os mais e menos em cada indicador;

- O AFMP disponibiliza um ranking global como conjugação dos diversos indicadores que foram analisados, embora seja reduzida a informação relativa ao distrito de Setúbal. Apenas 3 municípios figuram nos rankings globais;

- A elaboração de rankings exclusivos para a amostra permitiu evidenciar com maior detalhe o desempenho dos municípios em análise, quer através de um ranking global, quer dos rankings obtidos em cada indicador;

- O ranking global para o distrito confirma Alcácer do Sal, Almada e Grândola como os municípios mais bem posicionados e Santiago do Cacém com aquele que encerra a lista;

- Na análise à divulgação de indicadores nos Relatórios de Gestão da amostra, confirma-se que os mesmos assentam fundamentalmente em indicadores de carácter orçamental, económicos e/ou patrimonial;

- Os municípios do distrito de Setúbal apresentam um total de 159 indicadores diferentes, sendo 115 de natureza orçamental e 44 de cariz económico e patrimonial. Por outro lado, 3 municípios não apresentam qualquer indicador;

- Os indicadores ainda apresentam designações utilizadas na contabilidade empresarial, como é o exemplo do rácio Capital Próprio/Activo Líquido Total. Este é, conjuntamente com o rácio Fundos Próprios/Passivo Total aquele que é mais divulgado, não se repetindo contudo mais do que quatro vezes.

Assim e de uma forma geral, verifica-se que o conjunto de indicadores seleccionados para avaliar a gestão dos municípios tem como fonte de informação dois sistemas contabilísticos, a Contabilidade Patrimonial e a Contabilidade Orçamental, mais concretamente nos mapas de "Balanço", Demonstração dos Resultados" e "Mapas de Controlo Orçamental". Ou seja, nenhum dos indicadores previstos tem por base o sistema obrigatório de Contabilidade de Custos, exigida quer pelo POCAL, quer indirectamente pelo Regime Geral de Taxas (Lei n53-E/2006). Existe portanto, uma ausência de informação detalhada sobre a formação dos custos e dos proveitos, e que permitiria apoiar a gestão na tomada de decisão futura e simultaneamente tomar medidas correctivas adequadas e atempadas. Por outro lado, com a Lei $\mathrm{n}^{\circ} 66-\mathrm{B} / 2007$, de 28 de Dezembro, que estabelece o Sistema Integrado de Avaliação do Desempenho da Administração Pública (SIADAP), e o qual tem aplicação às entidades autárquicas, novas formas de avaliação de desempenho dos municípios se tornaram obrigatórias. De acordo com o SIADAP, a avaliação de desempenho de um município, assenta na criação e avaliação de metas que permitam aferir sobre a eficácia, eficiência e qualidade da gestão dessas entidades. Esta avaliação deve ser apresentada num Quadro de Avaliação e Responsabilização (QUAR).

Como linha de investigação futura pretendemos estudar uma nova perspectiva de análise de desempenho autárquico tendo por base a análise comparativa dos QUAR's dos diferentes municípios do distrito de Setúbal. Por outro lado, daremos seguimento ao presente estudo com a replicação da análise para os anos seguintes, permitindo uma análise evolutiva do desempenho dos municípios do distrito de Setúbal.

\section{REFERÊNCIAS}

AHMAD, Y.; BROUSSINE, M. The UK public sector modernization agenda. Public Management Review, v. 5, n. 1, p. 45-62, 2003. doi: 10.1080/1461667022000028852

AMARAL, F. Curso de direito administrativo. 2a Edição, v. 1, Almedina: Coimbra, 2002.

BARZELAY, M. The New Public Management: Improving Research and Policy Dialogue. 
Berkeley, CA: University of California Press. 2001.

CAIADO, A. Contabilidade de Gestão. $2^{\text {a }}$ Edição, Áreas Editora: Lisboa, 2002.

CARVALHO, J.; FERNANDES, M. J. CAMÕES, P.; JORGE, S. Anuário Financeiro dos Municípios Portugueses 2008. Ordem dos Técnicos Oficiais de Contas, Lisboa, 2010.

CARVALHO, J.; FERNANDES, M. J. CAMÕES, P.; JORGE, S. Anuário Financeiro dos Municípios Portugueses 2007. Fundação para a Ciência e a Tecnologia, Câmara dos Técnicos Oficiais de Contas, Tribunal de Contas, 2009.

CARVALHO, J.; FERNANDES, M. J. CAMÕES, P.; JORGE, S. Anuário Financeiro dos Municípios Portugueses 2006. Fundação para a Ciência e a Tecnologia, Câmara dos Técnicos Oficiais de Contas, Tribunal de Contas, 2008.

CARVALHO, J.; FERNANDES, M. J. CAMÕES, P.; JORGE, S. Anuário Financeiro dos Municípios Portugueses 2005. Fundação para a Ciência e a Tecnologia, Câmara dos Técnicos Oficiais de Contas, Tribunal de Contas, 2007.

CARVALHO, J.; FERNANDES, M. J. CAMÕES, P.; JORGE, S. Anuário Financeiro dos Municípios Portugueses 2004. Fundação para a Ciência e a Tecnologia, Câmara dos Técnicos Oficiais de Contas, Tribunal de Contas, 2006.

CARVAlHO, J.; FERNANDES, M. J.; TEIXEIRA, A. POCAL Comentado. $2^{\text {a }}$ Edição, Rei dos Livros, Porto, 2006.

CARValho, J.; MARTineZ, V. P.; PRADAS, L. T. Temas de Contabilidade Pública. Rei dos Livros, Lisboa, 1999.

CONSELHO Coordenador de Avaliação de Serviços (CCAS). Construção do QUAR Linhas de Orientação. 2008.

CORREIA, F. Contabilidade de custos ou a analítica no POCAL. Revisores e Empresas, Ano 4, n. 18, p. 7-26, 2002.

COSTA, T.; CARVAlHO, J. O Contributo da Contabilidade de Custos para a fixação das tarifas e preços na Administração local em Portugal. Revista de Administração e Contabilidade da Unisinos, v. 3, n.2, p. 189-199, Maio/Agosto 2006.

DECRETO-Lei no 116-84, de 6 de Abril - Organização dos serviços municipais.

DECRETO-Lei n $44-85$, de 13 de Setembro - Organização dos serviços municipais.

DECRETO-Lei $n^{\circ}$ 54-A/99, de 22 de Fevereiro - Plano Oficial de Contabilidade das Autarquias Locais.

GALERA, A.; RODRÍGUEZ, D.; HERNÁNDEZ, A. Identifying Barriers to the Application of Standardized Performance Indicators in Local Government. Public Management Review, v. 10, n. 2, p. 241-262, 2008. doi: 10.1080/14719030801928706

GOMES, P.; CARVALHO, J.; FERNANDES, M. J. Determinantes da adopção e desenvolvimento do sistema de contabilidade de custos nos municípios Portugueses. Contabilidade e Gestão - Portuguese Journal of Accounting and Management, n. 8, p. 11-40, Nov. 2009.

GONÇALVES, M.; CORREIA, C.; MARQUES, M.. Contabilidade Pública Autárquica em Portugal e a Informação divulgada em Regime de Caixa e de Competência: o caso de um município do distrito de Coimbra. Revista Universo Contábil, v. 7, n. 4, p. 156-178, Out.Dez. 2011. doi:10.4270/ruc.2011436 
HOOD, C. A public management for all seasons? Public Administration, v. 69, n. 1, p. 3-19, 1991. doi: 10.1111/j.1467-9299.1991.tb00779.x

LEI n ${ }^{\circ}$ 53-E/2006, de 29 de Dezembro, aprova o regime geral das taxas das autarquias locais.

LEI no 2/2007, de 15 de Janeiro, aprova a Lei das Finanças Locais.

LEI n. ${ }^{\circ}$ 66-B/2007 de 28 de Dezembro, estabelece o Sistema Integrado de Avaliação do Desempenho da Administração Pública (SIADAP).

MATA, C. A Contabilidade de Custos no POCAL: os municípios do Distrito de Setúbal. Provas Públicas, ESCE-IPS, Setúbal, 2010.

SERRA, S.; CARVALHO, J.; COSTA, A. A Demonstração de Resultados por Funções no Sector Público em Portugal. Revista Universo Contábil, v. 3, n. 2, p. 87-100, maio./ago. 2007.

TEIXEIRA, A. B.; PARDAL, P.; MATA, C.; TEIXEIRA, N. A Contabilidade Analítica no POCAL e o grau de implementação no Distrito de Setúbal. In: Jornadas Luso Espanholas de Gestão Científica, 20., ESCE-IPS, Setúbal, 2010. Anais..., 2010. CD-ROM. 